\title{
Possible Ways of Evaluation of Industrially Manufactured Means for Low-Bearing Terrain Strengthening Usable in Military Operations
}

\author{
Ota Rolenec ${ }^{\text {a, }}$, Tibor Palasiewicz ${ }^{\text {a }}$, Jaroslav Záleský ${ }^{\mathrm{a}}$, Jan Kyjovskýa ${ }^{\mathrm{a}}$, Ota Rolenec ${ }^{\mathrm{b}}$ \\ ${ }^{a}$ Department of Engineer Support, University of Defence, Kounicova 65, 66210 Brno, Czech Republic \\ ${ }^{b}$ Department of Engineer Technology, University of Defence, Kounicova 65, 66210 Brno, Czech Republic \\ Corresponding author: *ota.rolenec@unob.cz
}

\begin{abstract}
The article deals with determining possible criteria and costs for using modern means for low-bearing terrain strengthening in current operations. Particularly in the construction of bases and in fulfilling the tasks of mobility support during combat, it is necessary to comprehensively plan the use of these devices regarding their capabilities and the costs related to their total time of use. To select the optimal mean for use in a given task, it is proposed to assess the selected technical indicators, significantly affecting the purchase price. Given the importance of the financial costs of the whole process of using any means, the article proposes a procedure for calculating life cycle costs by using mathematical methods. When calculating the acquisition and use of devices for strengthening the terrain, it is necessary to evaluate both the required technical indicators and the life cycle costs of the means. The basic text premises are based on the analysis of documents solving the engineer mobility support of deployed troops and life cycle costs and on the results of structured interviews with commanders and members of airbases. The article aims to offer a potential user procedure for evaluating a new device or more means for strengthening the terrain among themselves already at the time of its acquisition based on the fulfillment of the given task.
\end{abstract}

Keywords - Costs calculation; mathematical methods; mobility support; terrain strengthening; military engineering.

\section{INTRODUCTION}

The evaluation of current foreign missions taking place over the past decades [1], [2] showed that mobility support task is an important issue for the survivability of units in deployment, which corresponds with Engineer tactical doctrine [3]. It is mainly the construction and maintenance of field bases, helipads, main supply routes, and, finally, the rescue of stuck or damaged military equipment.

With the increasing scope of deployment of units and equipment (including helicopters), the importance of constructing and maintaining military bases, military roads, and field-building complexes (field hospitals, helipads, etc.) represents an important task for engineers and logistics units. At present, it is essential from the point of view of mobility in these missions that at least a temporary infrastructure and helipad (prepared space reserved and used for helicopter takeoffs and landings), heliport (defined small airfield intended as a whole or as a part for helicopter arrivals, departures and ground movements of helicopters; the area is reinforced by appropriate means and is usually larger than a helipad) or runways for transport planes [4] be built at each military base or detached post.

In order to obtain an objective picture and relevant data on the current possibilities of the Army of the Czech Republic engineer troops in the field of terrain strengthening (building infrastructure at bases, landing areas for helicopters, construction of parking and other areas, strengthening the banks of crossing sites, rescuing vehicles), information was obtained in the form of structured interviews based on the experience of commanders of engineering units, air traffic logistics support units and air units. The main emphasis was on obtaining information about modular mobile systems (based on aluminum or plastic). Pre-formulated questions (a total of 8 issues) were asked to selected respondents and conducted during 2019.

The current requirements of the North Atlantic Treaty Organization (NATO) Army, Command for means to support the mobility of units are compatibility, lightweight, easy transportability and handling, pressure resistance, multipleuse, resistance to UV radiation and other weather conditions, resistance to chemical substances (fuels, oils), minimum 
storage requirements, long service life, speed of construction, repairability, costs [5], [6].

\section{MAterials AND MethoD}

This paper is based on a literature analysis dealing with engineer mobility support and materials showing possibilities of modern means for terrain strengthening. Obtained data are compared with results of structured interviews done with commanders and members of airbases. Using the Panel of Experts method, the authors of this article evaluated the weights of the criteria for individual types of assessed means. Synthesis methods were used to propose technical indicators assessment and costs calculation for the usage of suggested means.

The solved problem is marginally dealt with by the article [7], which solves the terrain relief effect on the transport cost. There are also works proposing an Algorithm for planning a full coverage route [8] and the Economic efficiency of plant construction [9]. These articles obtain data and equations whose calculation procedure can be used to design formulas in the next part of the text.

Many articles are devoted to researching path planning on $3 \mathrm{D}$ terrain or selecting the optimal route [10], [11]. However, these types of research do not address the possibility of terrain modification by means for low-bearing terrain strengthening, but they focus on calculations related to current terrain conditions. There are also many articles dealing with calculations in transportation [12], [14]. However, the authors of this article did not find materials that would comprehensively address the issue evaluation of industrially manufactured means for low-bearing terrain strengthening using mathematical models for technical indicators assessment and costs calculation, representing this research's aim.

\section{A. Evaluated Mobility Support Means}

Modern means for strengthening the terrain, e.g., plastic ITrac elements [15], special mats Mobi-Mat and Traction-Mat [16], hexagon paving tiles HexaDeck [17] or Terra-Tech tiles [18] have been used in NATO armies to road construction and improvement for many years. All the devices mentioned above are resilient, water and UV resistant, easy carrying and transportation, and quick and easy to assemble. Maybe, only one disadvantage of such means is physically demanding and time-consuming bottom landscaping. Underlying terrain must be as horizontal as possible. It does not apply to Mobi-Mat and Traction-Mat made by Deschamps company. These special mats can also be laid on rough terrain surfaces and can adapt to larger terrain unevenness. For further evaluation, the means for strengthening the terrain can be divided into the following categories:

- asphalt [19], [21],

- concrete [22],

- aluminium alloys [23], [24],

- plastics [25],

- other materials [26], [34].

Products based on asphalt or concrete can be considered above all as fixed (non-transferable) terrain consolidation means. These materials being fastened together with modified terrain are solid, resistant, and long-time durable. However, they are also heavy, non-moveable and their installation requires special equipment and much personnel employment.

Materials based on asphalt are being omitted because they cannot guarantee the dimensional stability of the surface from loading during higher temperatures, and the creation of the surface is technically demanding [35], [38]. Specific availability (refinery) represents the next disadvantage of such materials. The disadvantage of concrete surfaces is the difficulty in adhering to technological procedures during construction and compliance with its quality [39], [41]. Aluminum-based materials' disadvantage is primarily acquisition price and requirements for special laying equipment [42], [43].

For suitability assessment of particular materials and constructions useful for low-bearing terrain strengthening (vehicle recovery, base camp building in operations, infrastructure development), the requirement for forces' deployment time in missions abroad must be taken into account first of all. The deployment period usually ranges from 2 to 5 years (it can be even longer on permanent military bases).

Terrain consolidation devices evaluation aims to choose optimal material or structure that is adequate and suitable for usage in military operations. Many criteria influence lowbearing terrain strengthening mean, military base and infrastructure, or other field structures building up in operations abroad, as in Table I. The following criteria can be considered as the most important and decisive:

- the pace of construction (work process associated with the preparation, transport, and construction of surface required),

- personnel professional skills (requirements for qualification of workers expected to build the surface),

- equipment (requirements for working process support with equipment and devices),

- material availability (requirements for local material when building surfaces in missions abroad),

- mobility (portability and reuse capability),

- life service (duration time of surface ability to carry out a required function),

- environmental influence (an important factor in construction depending on climatic conditions),

- resistance (loading effect absorption ability),

- reparability (damaged surface reparation with reparation materials or its substitution by a new structure),

- price (acquisition cost of 1 square meter).

TABLE I

CRITERIA FOR EVALUATED CATEGORIES OF MEANS

\begin{tabular}{|c|c|c|c|c|c|}
\hline Criterion & $\frac{\frac{\hbar}{\pi}}{\frac{\pi}{2}}$ & ن⿺辶ّ & 当充 & 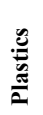 & Weight \\
\hline Pace of construction & 1 & 2 & 5 & 5 & 3 \\
\hline Skills requirement & 2 & 2 & 3 & 5 & 2 \\
\hline Equipment & 2 & 1 & 2 & 6 & 3 \\
\hline Material availability & 1 & 3 & 3 & 5 & 2 \\
\hline Mobility & 0 & 0 & 4 & 6 & 2 \\
\hline Life service & 4 & 6 & 5 & 4 & 2 \\
\hline Environmental influence & 3 & 3 & 5 & 5 & 1 \\
\hline Resistance & 4 & 6 & 5 & 3 & 2 \\
\hline Reparability & 3 & 4 & 2 & 5 & 1 \\
\hline Price & 3 & 6 & 1 & 4 & 2 \\
\hline
\end{tabular}


Using the Panel of Experts method, the authors of this article evaluated the considered categories of means for strengthening the terrain according to the above criteria. The range of point evaluation of the criterion was $0-6$ points, while $0-2$ means a negative effect, 3 means an average, and 4-6 a positive effect. In assessing the criteria, it was considered that they were all the maximization types.

The formula is used to calculate the overall score of the mean categories:

$$
C_{j}=\sum_{i}^{m} v_{i}^{j} \cdot B_{i}^{j}
$$

where $\mathrm{C}_{\mathrm{j}}$ is the overall score of the given mean category (in points), $v_{i}^{j}$ is the weight of the $\mathrm{i}^{- \text {th }}$ criterion in the $\mathrm{j}^{\text {th }}$ category, $\mathrm{B}_{\mathrm{i}}^{\mathrm{j}}$ is the point evaluation of the $\mathrm{i}^{\text {th }}$ criterion in the $\mathrm{j}^{\text {th }}$ category and $m$ is the total number of criteria. Based on the performed calculations, the total number of points for the evaluated categories is shown in the graph (Figure 1).

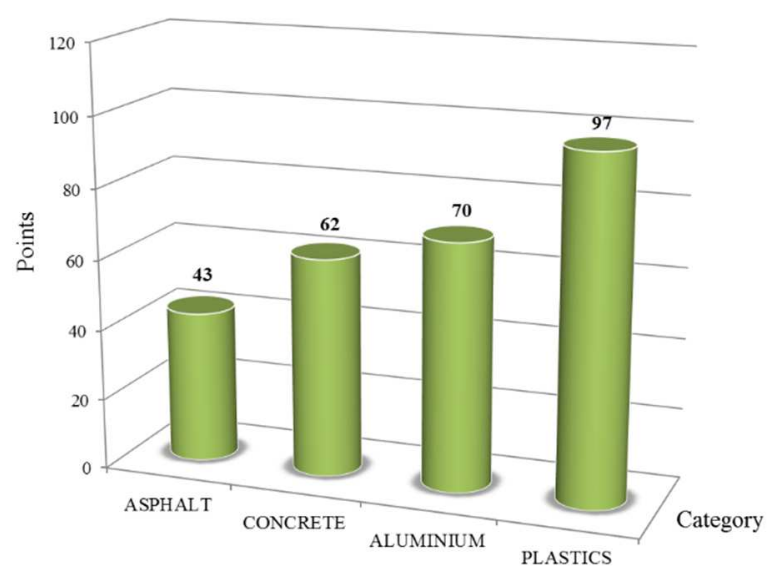

Fig. 1 Graphic representation of assigned points

The characteristics of devices for strengthening the terrain show that plastics appears to be the most suitable material. It represents the best evaluation of technical parameters within current requirements, i.e., compatibility, lightweight, easy transportability and handling, load resistance, multipleuse, resistance to UV radiation and chemicals (fuel, oils), minimum storage requirements, durability, speed construction, reparability, and price. The advantage of plastic means characteristics has been tested by the Department of Engineering Technology of the University of Defence in Brno [25].

\section{B. Possibilities of Using Modern Means for Terrain Strengthening in Operations}

Requirements for the scope, methods, forces and means in fulfilling the mobility support tasks within military engineering will always result from the specific activities of troops. The effort of all types of forces will be to ensure the movement of their units with the maximum use of resources that are immediately available to them. Before the beginning of the operation, it will be necessary to specify exactly what activities and to what extent the units of the engineer troops will perform the tasks of supporting both the land and air forces.
The speed and flexibility of the deployment of modern means for terrain strengthening can also be successfully used at first-echelon units of the task forces formation as an operational element for mobility support of troops in combat operations. During countermine operations, using devices for terrain strengthening will be advantageous, especially in terms of the possible terrain disruption in places of established passages caused by breaching technologies. Another possible use is offered, for example, in the reinforcing of access roads to the created passage in the minefield, the construction of paved areas for the safe storage of found and secured mines ready for removal, and subsequent destruction.

Establishing and maintaining any water-crossing sites shows that new technologies for strengthening low-endurable terrain are essential to support the flow of transport across watercourses (Figure 2 and 3). It includes arrival and departure routes to the water-crossing site and areas of concentration of transport means and material, checkpoints, and more. Here, the already mentioned modular plastic devices proved to be fully effective during the exercises.

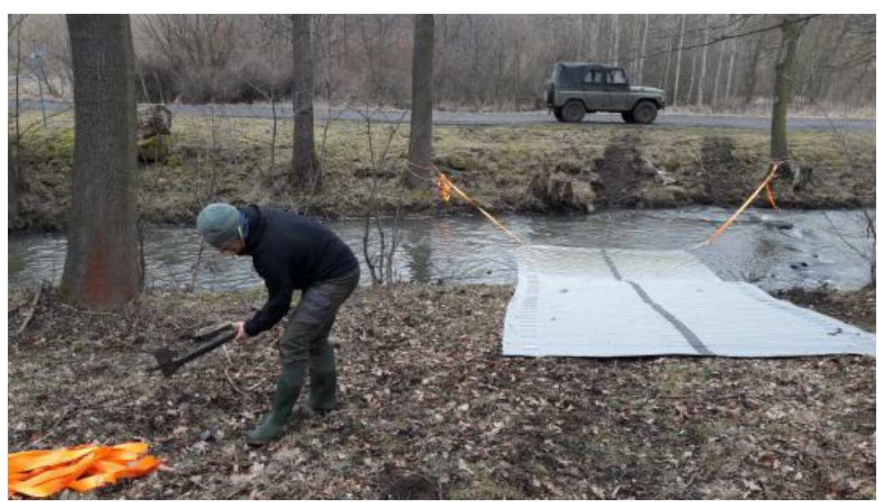

Fig. 2 The possible way of terrain fixing [25]

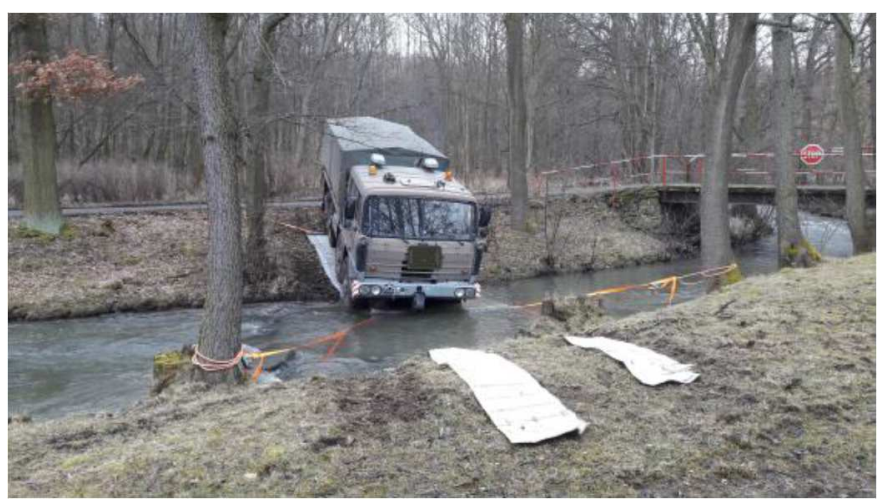

Fig. 3 Passes of the vehicle with plastic mats - both directions [25]

In addition to the classic methods of overcoming nonexplosive barriers using military vehicles, explosives, or by hand, it is possible to use plastic mats to overcome some types of barriers. It is primarily about overcoming scattered wire or anti-personnel wire barriers.

Among other tasks conducted in the use of means to strengthen the terrain in all types of operations belong:

- self-rescue of light and heavy wheeled vehicles,

- possible rescue of sunken vehicles,

- terrain strengthening while deploying truck cranes,

- construction of supply routes, 
- construction of helipads or heliports,

- construction of sites within the base's construction.

The execution of earthworks and construction works in a future military base, field hospital, helipad/heliport, or other field structures depends on on-site location, the results of a detailed terrain reconnaissance, and climatic conditions' influence the locality. It is, therefore, not possible to unambiguously determine and specify the scope of work in advance. Only an expert estimate is made, but it is always calculated so that it is as economically helpful as possible. Attention should be paid to the maximum use of local resources of raw materials, building materials, and construction systems. An especially important element of military bases is landing areas, which can be divided into groups according to the type of material used:

- solid landing surfaces based on the solidification of powder substances,

- constructions made of materials based on aluminum alloys:

- belts wound in spools,

- individual segments of panels,

- Constructions made of plastic-based materials:

- special plastic mats or strips,

- landing areas are composed of individual segments.

Structures formed by folding segments or mats have a wide range of uses. They do not require heavy equipment for laying and have almost the same parameters in strength and load capacity as aluminum segments. The indisputable advantage of this mobile system is the speed of construction, variability, simplicity, and simplicity in creating the required area (manual installation without the use of heavy equipment). Regarding the construction of helipads, the basic requirements of the Air Force apply, as stated in interviews with airport commanders, that the landing area must be light and solid, easy to transport, must meet multiple uses, easy assembly, and disassembly with a minimum number of people and equipment. Depending on the load capacity and the character of the terrain, it is possible to build four types of helipads:

- The area of untreated or slightly modified and sufficiently load-capacity terrain without higher demands on technology.

- The area of modified, sufficiently, or insufficiently load-capacity and dusty terrain using the technology of multilayer polyethylene mesh.

- The area of modified, sufficiently, or insufficiently load-capacity and dusty terrain using system components.

- Paved surface using precast concrete or monolithic concrete slabs, or asphalt surfaces.

\section{RESULTS AND DISCUSSION}

\section{A. Technical Indicators Assessment}

In practice, there are many of approaches to technical indicators comparison of assessed means to terrain consolidation. It turns out that there are large differences in the subjective interpretation of the possibilities of using these means. Mathematical methods have been necessarily adopted to assess the overall impact of all the above-defined indicators. Selected indicators (technical parameters), which also significantly affect the purchase price of assessed mean, include:

- device's universality of the use,

- resistance of the mean,

- reliability of the device,

- mean's transportability,

- mean's maintenance,

- device's impact on ecology.

The universality of using a modular system of structures for consolidating terrain has been required in NATO armies. In the first place, such devices must meet various use requirements in various areas of deployment, and most ground and air forces engineer support tasks fulfilling. If such used structure is single purpose, e.g., suitable only for helipad building or water obstacle banks' surface consolidation, it will be more appropriate to choose such terrain strengthening structures of broader usage capability even if their price will be higher. Plastic devices are light, man-portable, modular safeguarding systems useful to the path and road hardening, parking and purpose-build areas, construction of helipads and heliports, the building of aircraft station areas, building of protective walls against dust and wind, and finally for damaged vehicle recovery.

Load that the structure can bear has to be at least as produced by particular ground or air equipment respectively material. Maximum load is usually specified in $\mathrm{kg} . \mathrm{m}^{-2}$, but more precise load magnitudes expression using MPa seems to be more applicable. All mentioned structures made of plastic materials are mechanically and chemically resistant, extreme temperature resistant (from $-40^{\circ} \mathrm{C}$ to $+80^{\circ} \mathrm{C}$ ), high resistance against acids, fuels and oil products, UV radiation, and environmentally friendly.

The reliability of the means for strengthening the terrain is determined according to the reliability of individual parts and connections of the given device. Parts are interlocked to each other in the system, and they can affect themselves. For mathematical expression, it is assumed that the condition of device's one part is not affected by the condition of another one. Parts in the system are mutually independent, and a particular part is either in top or poor condition. The top condition will happen if all parts run reliably. The reliability of such a system is at most equal to the reliability of the worst part. Terrain consolidation devices' reliability mathematical model has been developed using deduction from formula published in [44]. If $\mathrm{S}(\mathrm{t})$ denotes the reliability of a construction with $\mathrm{n}$ mutually independent parts with the reliability $\mathrm{S}_{\mathrm{i}}(\mathrm{t}), \mathrm{i}=1 \ldots \mathrm{n}$, then for $\forall \mathrm{t} \in\langle 0, \infty)$ :

$$
\begin{gathered}
S(t)=\prod_{i}^{n} \operatorname{Si}(t) \leq \min _{i} \operatorname{Si}(t) \\
F(t)=1-\prod_{i}^{n} \operatorname{Si}(t) \geq \max _{i} F i(t)
\end{gathered}
$$

where $F(t)$ is the distribution function of a random variable (time between construction failures) and $\mathrm{Fi}(\mathrm{t})$ is the distribution function of a random variable of the $i^{\text {-th }}$ part of the structure (time between failures of the $\mathrm{i}^{- \text {th }}$ part of the structure).

The whole mean body's reliability consisted of parts depending on the reliability of its system and individual components. If one of the parts is damaged, the whole structure will be damaged (e.g., the whole landing area for the helicopter). To perform the calculation, it is necessary to substitute the input data into the created formulas. These 
data are represented by functional reliability characteristics of particular structures' components. They can be gained from statistical data processing, expert estimation or information provided by the producer. Following data can be used under military conditions to determine reliability characteristics:

- from logistic information system,

- from the producer (importer), broker,

- from user.

Weight and size are significant variables to calculate transportation costs. It is important to count on the essential equipment used for realizing the initial operation phase in foreign areas regarding limited air and transport means supporting transport to the operational area. It is necessary to choose a material of the lowest potential weight and small size, keeping its high load-carrying capacity and resistance to climatic influences. Application of light mobile terrain consolidation means plastic seems to be more useful in the initial operation phase. As compared to steel or aluminum systems, they offer high efficiency together with the same size conservation.

Terrain strengthening construction has to be as spacesaving as possible when folded to be transported on the body of a truck, on an aircraft's or helicopter's deck. Transported terrain consolidation constructions have to be appropriately embarked and secured with proper means preventing excessive movement to each other and transportation device walls [45]. Airbags, fastenings straps, battens or anti-slip devices can be used for fixation purposes.

The ISO 1C storage container (variety of alternatives) is unified transportation mean applied and used in many armies. Its device design meets aircraft Hercules C-130 transportation requirements. Container makes material of $30,09 \mathrm{~m}^{3}$ (inner size 2,33 x 5,87 x 2,20 m) transportation and storage possible. The weight of the empty container is about $2500 \mathrm{~kg}$, and the load capacity is $21500 \mathrm{~kg}$.

Terrain strengthening structures without chassis (they are not part of military equipment) should be loaded into a transportation vehicle following certain requirements. Two limiting requirements have been determined:

$$
\begin{gathered}
v \text { de } \leq \text { vct } \\
m \text { de } \geq \text { umct }
\end{gathered}
$$

where $V_{\mathrm{de}}\left[\mathrm{m}^{3}\right]$ is the volume of the construction for strengthening the terrain, $V_{c t}\left[\mathrm{~m}^{3}\right]$ is the internal usable capacity of the container or means of transport, $m_{\mathrm{de}}[\mathrm{kg}]$ is the weight of the construction for strengthening the terrain and $\mathrm{um}_{\mathrm{ct}}[\mathrm{kg}]$ is the useful (permitted) load capacity of the container or means of transport.

Terrain consolidation structure size and shape does not usually make a full load of containers possible. So-called material palletization can act as a partial factor of limitation when each state complies with the rules established by its own standards. In the case of the Army of the Czech Republic, Czech Defence Standard C̆OS 399006 Military pallets, packages, and containers [46] regulates the stacking height of the transported unit to $1,6 \mathrm{~m}$, including the height of the pallet. Incompatibility of container size and size of strengthening means does not provide ideal storage. Both vertical and horizontal way of storage is usually used for such constructions' transportation. The capacity of the container $\left(o_{c t}\right)$ may be expressed, in compliance with the set conditions not exceeding the maximum load, as follows:

$$
\text { oct }=v \mathrm{de} / v \mathrm{ct}
$$

New modern technologies of industrially produced terrain consolidation means based on plastic materials require minimal maintenance, usually limited to basic cleaning of their surface in whole or their particular components. Cleansing based on local usage conditions can be applied to the demand. In case of usage in multinational operations, blown sand or small stones are removed from the used mean's surface. The excessive worn out or the end of their life cycle is not expected due to their resistance characteristics. However, the damage or destruction of the mean can be caused by hostile activity. These mobile systems allow immediate replacement of individual parts with new ones. In the unification of mobile means for strengthening the terrain, supplying spare parts will be significantly simplified.

At the end of operations (missions), allied forces' units often leave a significant ecological footprint in their working areas during military base decamping and abandonment. These ecological problems are present on the whole basecamp, especially on places where permanent means of terrain consolidation as concrete, asphalt, or wood were used (basecamp infrastructure, parking areas, storages, various utility areas, heliports etc.). Although plastic or aluminumbased means cannot completely eliminate prospective ecological accidents, it can certainly eliminate the ecological burden during basecamp's restoration to the original state. Handling with such devices is easy, time-saving, and thanks to their chemical and mechanical resistance to oil products or UV radiation, significant ecological damages do not occur. Constructions made of plastic or aluminum are environmentally friendly, and they do not excessively burden the environment.

The problem of terrain strengthening devices disposal has been technologically resolved by the ecological disposal of plastic means or recycling means made of aluminum. In aluminum structures recycling, the total volume of waste is usually limited to a minimum, and the reuse of such base material for further production decreases the price of new products.

\section{B. Proposal of Costs Calculation}

To evaluate the costs of all devices introduced into use in any army, aluminium and plastic means for strengthening the terrain, it is not possible to focus only on a simple comparison of input (investment) costs. It is necessary to monitor all costs associated with the selected product in all phases of its life cycle, i.e., product research and development, purchase, operation (use), and disposal (elimination). Such costs are referred to as the Life Cycle Costs (LCC) of the product or service. It is the sum of direct, indirect, and otherwise related incurred costs or an estimate of the incurred costs [47]. The content of individual components of life cycle cost is not uniformly understood or defined. For example, if some of the evaluation items are the same for all evaluated terrain reinforcement products, these items are usually completely and intentionally omitted.

The purchase price of a product usually includes, among other things, research and development costs. In the area 
of fulfilling the tasks of engineer support in the reinforcement of the terrain with industrially produced plastic devices, it is generally not assumed that the Ministry of Defence would individually develop structures for terrain strengthening based on plastics due to the existence of the already mentioned plastic means for overcoming the terrain. If this were the case, then this type of cost must be considered.

The only and most important criterion used to select the optimal product is the purchase price (PPde). The product's price may or may not include financial costs, transport, testing, approval process, documentation, training, maintenance during the warranty period, spare parts for accessories, tools, etc. [48]. Purchase costs can consist of:

- purchase price,

- input costs for production - costs for the production of a test sample during the implementation of the project,

- manpower - costs of manpower training - initial training in the use, for assembly and disassembly, maintenance and possible repairs,

- documentation - initial costs of delivery of original printed and electronic documentation and translations,

- support equipment - initial costs for the acquisition, installation, and transport of support equipment (tools, workshop equipment),

- transport costs - transport costs to engineer and logistics units,

- costs of implementation new devices - costs of implementing new means into the Logistics Information System,

- other costs, if any.

In connection with the operation (use) of the purchased device, operating costs are incurred. This is a significant component of the LCC assessment, especially for products with a longer life cycle. Operating costs may or may not exceed the purchase price of the product. Operating costs can consist of:

- storage costs - annual costs associated with the storage of the product (costs of premises, processes, or equipment),

- revision costs - determined by the device manufacturer.

- maintenance and repair costs:

- consumables costs (annual consumables costs),

- manpower - annual labour costs for preventive maintenance and repairs,

- costs for repairs at the supplier - annual costs of repairs outside the logistics support system,

- documentation update costs - annual costs for updating printed and electronic documentation and translations,

- other maintenance costs, if any,

- supply costs:

- consumables replacement costs - annual costs of consumable purchases,

- transport costs - annual costs of transport of replaced and repaired parts,

- other supply costs, if any.

Regular revisions (inspections) may be required to verify the technical condition and safety of the means for strengthening the terrain. Even though some manufacturers of these products recommend performing preventive inspections only once every two years, it is necessary to calculate these costs. The cost of carrying out revisions during the operation can be determined as follows:

$$
\text { CRede }=\text { Mre } \cdot \text { win } \cdot \frac{t o}{p r e}
$$

where $\mathrm{CRe}_{\mathrm{de}}$ [monetary unit] is the estimated revision costs of the mean, $\mathrm{M}_{\mathrm{re}}$ [time unit] is the estimated time required to revise the mean, $w_{\text {in }}$ [monetary/time unit] is the inspection's worker wage, $t_{0}$ [time unit] is the evaluation period, e.g., length of operation and $p_{r e}$ [time unit] is the required frequency of revisions. $\mathrm{t}_{\mathrm{o}} / \mathrm{p}_{\mathrm{re}} \in \mathrm{N}$ to express the whole number of revisions in the evaluated period. If it is necessary to calculate the cost for the device's entire life, it is possible to exchange $t_{0}$ for life cycle length $\left(t_{L C}\right)$.

Product maintenance and repair costs are part of operating costs and represent another important area. This group of costs is difficult to plan, and it is necessary to work with certain risks. Several basic aspects should be considered when calculating the total costs of repairs, such as the mean time between product damage, the supplier's business policy, the size of reserves in the form of allocated spare parts, and financial resources for repairs caused by improper handling or human error [48]. The calculation of the total costs of repairs is determined by the probability of damage and the sum of all significant cost items (including the estimated reserve). Plastic devices for terrain strengthening do not contain any preservation-intensive parts, and their maintenance consists mainly of cleaning the load surfaces. Maintenance costs can be planned at the time of purchase:

$$
\text { CMade }=\mathrm{M} \cdot w \mathrm{ma}+\mathrm{CSma}
$$

where $\mathrm{CMa}_{\mathrm{de}}$ [monetary unit] is the total costs of maintenance of the device for the period, M [time] is the total maintenance time, $\mathrm{w}_{\mathrm{ma}}$ [monetary/time unit] is the maintenance worker's wage, $\mathrm{CS}_{\mathrm{ma}}$ [monetary unit] is the spare parts costs related to maintenance.

Repair costs can only be estimated based on user experience. The device provider should provide a maintenance system that eliminates the need for repairs caused by internal factors of the device (e.g., production failure). Correction due to external factors (operator error, enemy activity, adverse climatic conditions, etc.) can be expressed by a probable damage factor:

$$
\text { CRpde }=(R d e \cdot w r e+\mathrm{CPde}) \cdot F d
$$

where $\mathrm{CRp}_{\mathrm{de}}$ [monetary units] is the total estimated costs of mean repairs for the period, $\mathrm{R}_{\mathrm{de}}$ [time] is the total estimated time required for repairs, $\mathrm{w}_{\mathrm{re}}$ [monetary/time unit] is the repair's worker wage, $\mathrm{CP}_{\mathrm{de}}$ [monetary units] is the spare parts costs in connection with repairs and $F_{d}$ is the damage factor which represents the frequency of damage due to external factors.

The damage factor is expressed by the frequency of damage over the measured period. The mathematical expression is as follows:

$$
F d=\frac{\text { MTde }}{t \mathrm{LC}} \cdot t o
$$


where MTde [time unit] is the mean time between lesions, $\mathrm{t}_{\mathrm{LC}}$ [time unit] is the life cycle length and $t_{0}$ [time unit] is the evaluation period, e.g., length of operation.

It is advantageous to include the so-called Reserve in calculating maintenance and repair costs, which is an item allowing to express the inaccuracy of the planning estimate of selected costs for various objective reasons. The reserve is calculated based on the specific case and type of device or conditions of use. How high the reserve will be is up to the user. This decision is one of the tasks of risk management. The amount of the reserve should then be adjusted based on an analysis of history and experience.

The total amount of operating costs $\left(\mathrm{OC}_{\mathrm{de}}\right)$ consists of the sum of the above items. Formulas did not express all components of operating costs due to their repetition, simplicity, or just their expression by the manufacturer.

Elimination costs $\left(\mathrm{EC}_{\mathrm{de}}\right)$ represent an elementary sum of costs associated with the disposal of the purchased device for strengthening the terrain and related services (own product, spare parts, administrative costs, costs of removal to the place of disposal, etc.) and have a decisive influence on LCC of the device. Reverse logistics examines the area of disposal, liquidation, and use of unnecessary assets, which are physically or morally obsolete. Disposal costs can be expressed as a negative value if the mean is sold.

The service life determines the total time of possible use of the evaluated device. The service life can be stated, for example, by the number of repeated assemblies and disassembles, the number of crossings of vehicles, or the number of landings and take-offs of helicopters. LCC of the device for strengthening the terrain is the sum of the costs determined in the previous sections of the text. According to the user's needs, they can be extended by other monitored areas:

$$
\text { LCCde }=\text { PPde }+ \text { OCde }+ \text { ECde }
$$

Since the life cycle of products for terrain reinforcement is usually not the same (higher quality product has higher life cycle costs because it is used longer) and, e.g., pressure on the structure is not equal (more durable product with the higher load usually has higher LCC). It is not sufficient to objectively compare two or more devices for strengthening the terrain only with the total cost values of their life cycles. Therefore, it is necessary to assess the life cycle costs per time unit (e.g., year).

\section{CONCLUSION}

When calculating the acquisition and use of devices for strengthening the terrain, it is necessary to evaluate both the required technical indicators and the life cycle costs of the means. In this article, an evaluation of the most important technical indicators for these means was proposed using mathematical models. Furthermore, a cost calculation proposal was created to evaluate the feasibility of using the proposed means in all types of military operations. Using these mathematical models, logistics authorities can better assess the acquisition of specific means, for example, in the construction of bases concerning economic viability.

The authors will, in their future work, focus on the endurance testing of means above for low-bearing terrain strengthening in cooperation with other departments of the
University of Defence by using a similar approach described in the article [49] and are also going to assess the environmental impact of the use of metal and aluminum structures compared to commonly used materials in the construction of roads and paths, as described in [50]. It is also important to propose their incorporation into the military or, more precisely, engineer units to fulfill required tasks and calculate periods of various constructions to use in the system of command and control.

\section{ACKNOWLEDGMENT}

The authors are grateful for the Czech Republic Ministry of Defense development program "Advanced Automated Command and Control System II” PASVŘ II/DZRO K-110.

\section{REFERENCES}

[1] I. S. Griffith and N. D. Zimmerly, "Engineers support U.S. border patrol,” Engineer, vol. 44, pp. 16-19, 2014.

[2] P. Merriman and K. Peters, "Military mobilities in an age of global war, 1870-1945," J. of Hist. Geo., vol. 58, pp. 53-60, Jul. 2017.

[3] ATP-3.12.1 Allied Tactical Doctrine for Military Engineering, NATO Standardization Office (NSO): Brussel, Belgium, 2016.

[4] D. Zhang, L. Cai, and S. Zhou, "An airfield soil pavement design method based on rut depth and cumulative fatigue," J. of Adv. Transp., vol. 2019, pp. 1-11, Jan. 2019.

[5] M. Wesołowski and A. Wróblewska, "Analysis of the operating conditions of mobile composite airfield pavements," Road Mat. and Pav. Desing, pp. 1-21, Jun. 2019.

[6] M. Wesołowski, P. Barszcz, and K. Blacha, "Mobile composite airfield element of security and reliability in air transport," $J$. of Konbin, vol. 44, pp. 309-320, Dec. 2017.

[7] C. Ma and Y. Zhang, "Effect of terrain relief on the transport cost on road of biomass raw materials: Energy conservation study of 9 cities and counties in China," J. of Env. Man., vol. 274, p. 111212, Nov. 2020 .

[8] L. Yangyang, R. Yu, L. Bin, and Ch. Xuyang, “Algorithm for planning full coverage route for helicopter aerial spray," Tr. of the Ch. Soc. of Agr. Eng., vol. 36, no. 17, pp. 73-80, 2020.

[9] E. Shagiakhmetova, Y. Medyanik, L. Gimadieva, D. Vakhitova, and I. Yarullina, "Economic efficiency of plastic recycling plant construction," in IOP Conf. Ser.: Mat. Sc. and Eng., Kazan, Russian Federation, vol. 890, 2020, p. 012114.

[10] Y. Hara and M. Tomono, "Moving object removal and surface mesh mapping for path planning on 3D terrain," $A d v$. Rob., vol. 34, no. 6, pp. 375-387, Jan. 2020.

[11] J. Drozd and J. Neubauer, „Use of an aerial reconnaissance model during the movement of oversized loads," J. of Def. Mod. \& Sim., vol. 17 , no. 4 , pp. 447-456, Jul. 2019.

[12] A. V. Lagerev and I. A. Lagerev, „,Designing Supporting Structures of Passenger Ropeways of Minimum Cost Based on Modular Intermediate Towers of Discretely Variable Height," Urb. Rail Tr., vol. 6 , no. 4 , pp. $265-277$, Nov. 2020.

[13] O. Čokorilo, I. Ivković, and. S. Kaplanović, "Prediction of exhaust emission costs in air and road transportation, " Sustainability, vol. 11, no. 17 , p. 4688 , Aug. 2019.

[14] R. Janulionis, G. Dundulis, and A.Grybėnas, ,Numerical research of elastic-plastic fracture toughness of aged ferritic-martensitic steel,“ Eng. Fail. An., vol. 120, no. 8, p. 105070, Nov. 2020.

[15] (2020) Products of company ROLA-TRAC. [Online]. Available : http://www.rola-trac.co.uk/product/i-trac/

[16] (2020) Products of company Deschamps. [Online]. Available: http://www.mobi-mat-chair-beach-access-dms.com/

[17] (2020) Hexadeck Heavy-duty Tent Flooring. [Online]. Available: http://signaturecorp.com/ events/hexadeck/

[18] (2020) Products of company Prima. [Online]. Available: http://www.primadirect.co.uk/

[19] Z. Fu, W. Shen, Y. Huang, G. Hang, and X. Li, "Laboratory evaluation of pavement performance using modified asphalt mixture with a new composite reinforcing material," Int. J. of Pav. Res. and Tech., vol. 10, no. 6 , pp. 507-516, Nov. 2017. 
[20] P. K. D. Maeijer, W. V. D. Bergh, and C. Vuye, "Fiber bragg grating sensors in three asphalt pavement layers," Infrastructures, vol. 3, no. 2, p. 16, Jun. 2018.

[21] W. Bańkowski, "Evaluation of fatigue life of asphalt concrete mixtures with reclaimed asphalt pavement," App. Sci., vol. 8, no. 3, p. 469, Mar. 2018.

[22] I. N. Grubeša, I. Barišić, T. Keser, and M. Vračević, "Wearing characteristics assessment of pervious concrete pavements," Road Mat. and Pav. Desing, vol. 20, no. 3, pp. 727-739, Apr. 2019.

[23] G. Ingarao, P. C. Priarone, Y. Deng, and D. Paraskevas, "Environmental modelling of aluminium based components manufacturing routes: Additive manufacturing versus machining versus forming," J. of Clean. Prod., vol. 176, pp. 261-275, Mar. 2018.

[24] A. de Rubeis, P. D. Mascio, F. Montanarelli, and L. Moretti, "Design of a temporary surface-level helipad paved with aluminium mats," Eu. Transp., vol. 2019, no. 72, p. 5, Jun. 2019.

[25] K. Cibulová and J. Sobotka, "Utilization of perspective materials for negotiation of watercourses," in Proc. IEEE Int. Conf., Transp. Means 2019, vol. 1, 2019, pp. 655-659

[26] M. Ryms and E. K. Radziemska, "Possibilities and benefits of a new method of modifying conventional building materials with phasechange materials (PCMs)," Const. and Build. Mat., vol. 211, pp. 10131024, Jun 2019.

[27] C. Rodríguez, I. Miñano, M. Aguilar, J. Ortega, C. Parra, and I. Sánchez, "Properties of concrete paving blocks and hollow tiles with recycled aggregate from construction and demolition wastes," Materials, vol. 10, no. 12, p. 1374, Nov. 2017

[28] C. Maharaj, D. White, R. Maharaj, and C. Morin, "Re-use of steel slag as an aggregate to asphaltic road pavement surface," Cog. Eng., vol. 4, no. 1, p. 1416889, Jan. 2017.

[29] S. Du, J. Wu, O. AlShareedah, and X. Shi, "Nanotechnology in cement-based materials: a review of durability, modeling, and advanced characterization," Nanomaterials, vol. 9, no. 9, p. 1213, Sep. 2019.

[30] M. Cabrera, J. Rosales, J. Ayuso, J. Estaire, and F. Agrela, "Feasibility of using olive biomass bottom ash in the sub-bases of roads and rural paths," Const. and Build. Mat., vol. 181, pp. 266-275, Aug. 2018.

[31] R. H. Latief, "Evaluation of the performance of glasphalt concrete mixtures for binder course," Int. J. on Adv. Sc., Eng. and Inf. Tech., vol. 9, no. 4, pp. 1251-1259, Aug. 2019.

[32] T. Imjai, K. Pilakoutas, and M. Guadagnini, "Performance of geosynthetic-reinforced flexible pavements in full-scale field trials," Geotextiles and Geomembranes, vol. 47, pp. 217-229, Apr. 2019.

[33] J. S. Tingle, "Mechanistic analyses of geosynthetic reinforced aggregate road test sections," Transp. Res. Record: J. of the Transp. Res. Board, vol. 2673, no. 12, pp. 783-797, Sep. 2019.

[34] K. H. Mamatha and S. V. Dinesh, "Performance evaluation of geocellreinforced pavements," Int. J. of Geot. Eng., vol. 13, no. 3, pp. $277-$ 286, May. 2019

[35] S. Wu and B. Muhunthan, "A mechanistic-empirical model for predicting top-down fatigue cracking in an asphalt pavement overlay," Road Mat. and Pav. Desing, vol. 20, no. 6, pp. 1322-1353, Aug. 2019.

[36] Z. Refaa, M. R. Kakar, A. Stamatiou, J. Worlitschek, M. N. Partl, and M. Bueno, "Numerical study on the effect of phase change materials on heat transfer in asphalt concrete," Int. J. of Ther. Sc., vol. 133, pp. 140-150, Nov. 2018.

[37] Y. Du, J. Chen, Z. Han, and W. Liu, "A review on solutions for improving rutting resistance of asphalt pavement and test methods," Const. and Build. Mat., vol. 168, pp. 893-905, Apr. 2018.

[38] R. Buhari, M. M. Rohani, and S. Puteh, "Pavement life variation with material characteristics, road profiles and environmental effects," Int. J. on Adv. Sc., Eng. and Inf. Tech., vol. 8, no. 6, pp. 2386-2392, Dec. 2018.

[39] A. Vaitkus, T. Andriejauskas, O. Šernas, D. Čygas, and A. Laurinavičius, "Definition of concrete and composite precast concrete pavements texture," Transport, vol. 34, no. 3, pp. 404-414, May 2019.

[40] L. Ferrara, T. V. Mullem, M. C. Alonso, P. Antonaci, R. P. Borg, E. Cuenca, A. Jefferson, P. L. Ng, A. Peled, M. R. Flores, M. Sanchez, C. Schroefl, P. Serna, D. Snoeck, J. M. Tulliani, and N. D. Belie, "Experimental characterization of the self-healing capacity of cement based materials and its effects on the material performance: A state of the art report by COST Action SARCOS WG2," Const. and Build. Mat., vol. 167, pp. 115-142, Apr. 2018.

[41] C. Farrugia, R. P. Borg, L. Ferrara, and J. Buhagiar, "The application of lysinibacillus sphaericus for surface treatment and crack healing in mortar," Front. in Built Env., vol. 5, p. 62, Apr. 2019.

[42] L. Cai, D. Zhang, S. Zhou, and W. Xu, "Experimental study on the fatigue performance of pavement structures made of AAHSP," Int. $J$. of Pav. Eng., pp. 1-11, Jun. 2019.

[43] G. Çam and G. İpekoğlu, "Recent developments in joining of aluminum alloys," Int. Jour. Adv. Manuf. Technol., vol. 91, pp. 1851-1866, Jul. 2017

[44] Z. Karpíšek and P. Jelínek, "Stochastické metody analýzy spolehlivosti," in An. dat 01/II - Mod. stat. met., vol. 1, 2001, pp. 109-127.

[45] M. Vlkovský, "Impact of vehicle type and road quality on cargo securing," Comm. - Sc. Lett. of the Un. of Zilina, vol. 22, pp. 9-14, Jan. 2020.

[46] Ceský obranný standard 399006 Vojenské palety, svazky a kontejnery, Úráad pro obrannou standardizaci, katalogizaci a státní ověřován jakosti: Prague, Czech Republic, 2010

[47] G. F. Huseien and K.W. Shah, "Durability and life cycle evaluation of self-compacting concrete containing fly ash as GBFS replacement with alkali activation," Const. and Build. Mat., vol. 235, no. 117458 , Feb. 2020.

[48] P. Butorová, “Aspekty CALS v akvizičním procesu AČR,” Ph.D. dissertation, Dept. Log., University of Defence, Brno, Czech republic, 2010

[49] M. Manosalvas-Paredes, N. Lajnef, K. Chatti, K. Aono, J. Blanc, N. Thom, G. Airey, and D. Lo Presti, "Data compression approach for long-term monitoring of pavement structures," Infrastructures, vol. 5, no. 1 , p. 1 , Dec. 2019.

[50] F. S. Handayani, F. P. Pramesti, M. A. Wibowo, and A. Setyawan, "Estimating and reducing the release of greenhouse gases in local road pavement constructions, "Int. J. on Adv. Sc., Eng. and Inf. Tech., vol. 9, no. 5, pp. 1709-1715, Oct. 2019. 